\title{
STUDY OF LONE WORKING MAGNETIC RESONANCE TECHNOLOGISTS IN WESTERN AUSTRALIA
}

\section{TRACY ANNE DEWLAND, LAUREN NICOLE HANCOCK, SIMONE SARGEANT, REBECCA KIM MIN-AE BAILEY, RODGER ALLAN SARGINSON, and CURTISE KIN CHEUNG NG}

Curtin University, Perth, Australia

Discipline of Medical Imaging, Department of Imaging and Applied Physics

\begin{abstract}
Objectives: It is recommended that magnetic resonance (MR) technologists should not work alone due to potential occupational health risks although lone working is legally acceptable. The objective of this study was to investigate the current situation of lone working MR technologists in Western Australia (WA) and any issue against the regulations. Materials and Methods: A questionnaire regarding the issues of occupational health of lone working MR technologists was developed based on relevant literature and distributed to WA MR technologists. Descriptive (percentage of frequency, mean and standard deviation) and inferential statistics (Fisher's exact, $\mathrm{Chi}^{2}$ and $\mathrm{t}$ tests, and analysis of variance) were used to analyze the responses of the yes/no, multiple choice and $5 \mathrm{pt}$ scale questions from the returned questionnaires. Results: The questionnaire response rate was $65.6 \%$ (59/90). It was found that about half of the MR technologists $(45.8 \%, 27 / 59)$ experienced lone working. The private magnetic resonance imaging (MRI) centers were more likely to arrange technologists to work alone $(p<0.05)$. The respondents expressed positive views on issues of adequacy of training and arrangement, confidence and comfort towards lone working except immediate assistance for emergency (mean: 3 ). Factors of existence of MRI safety officer $(p<0.05)$ and nature of lone working $(p<0.001-0.05)$ affected MR technologists' concerns. Conclusions: Lone working of MR technologists is common in WA especially in private centers. The training and arrangement provided seem to be adequate for meeting the legal requirements. However, several areas should be improved by the workplaces including enhancement on immediate emergency assistance and concern relief.
\end{abstract}

Key words:

Australia, Lone working, Magnetic resonance imaging safety, Magnetic resonance technologist, Occupational health

\section{INTRODUCTION}

Working alone is an occupational health concern. The risk of injury would be increased as a lone worker may be unable to get immediate support when any emergency happens [1]. Although the regulations governing lone working vary across different countries, it is generally acceptable if risk assessment and establishment of the safe working environment (including provision of adequate training) are completed by an employer before assigning an employee to work alone [1,2].
In some high-risk working environments such as magnetic resonance imaging (MRI) departments, recommendations have been provided by their corresponding professional bodies such as American College of Radiology (ACR) [3] and The Royal Australian and New Zealand College of Radiologists (RANZCR) [4] to discourage magnetic resonance (MR) technologists from working alone because of the high potential risks. MRI was recognized as one of the top 10 health device technology hazards by the ECRI Institute (previous

Received: April 5, 2013. Accepted: November 22, 2013

Corresponding author: C.K.C. Ng, Discipline of Medical Imaging, Department of Imaging and Applied Physics, Curtin University, GPO Box U1987, Perth, Western Australia 6845, Australia (e-mail: curtise.ng@curtin.edu.au; curtise_ng@yahoo.com.hk). 
collaborating center of the World Health Organization) in 2010 [5].

Some potential occupational health risks related to MR technologists working alone include fatigue, projectile, quench, patients' aggressive behaviors and anxiety [6]. Fatigue is a potential risk since MR technologists are required to operate MRI machines [1]. Improper operation can lead to serious consequences to the personnel in the vicinity including the MR technologists [3].

There was a case that an MR technologist did not check hair pin removal for a patient before letting her enter an MRI scanning room. One of her pins became a projectile under the influence of the strong magnetic field of the scanner and penetrated through the patient's body into her stomach, which could also happen to the MR technologist [7]. Liquid helium used for maintaining the electromagnet of the MRI machine becomes gaseous when a magnet quench (shutdown) occurs. Some of the helium gas may replace oxygen in the scanning room leading to MR technologist's asphyxiation if the ventilation for the helium is not functioning properly [3,6-9].

A small number of patients may present aggressive behaviors to medical imaging technologists $[6,10,11]$. Patients' anxiety which can be triggered by, for example, high-level acoustic noise during MRI examinations [3,7,12] would fuel their aggression [11]. The lone working MR technologists can also feel anxious when facing patients' aggression [10], which in turn may affect the technologists' mental healthiness [13]. Although these occupational health risks could happen to any MR technologist, technologists' attention to safe operation procedures would be affected more easily in the lone working conditions, leading to increased risk [4]. Working alone, i.e. without access to immediate support, can also increase the risk severity to technologists [1].

Before the introduction of the MR safety guidelines [3,4], it had not been uncommon for MR technologists to be required to work alone [6,14]. It is important to investigate the current situation of lone working MR technologists in Western Australia (WA) and any issues that may go against the general regulations, such as training and arrangement for the safety of lone working MR technologists [1,2].

\section{MATERIALS AND METHODS}

A total of 17 public and private MRI departments in WA metropolitan and rural areas were asked to take part in this study in June 2012. These included all (14) public and private centers providing MR examinations fully subsidized by the government authority, Medicare Australia and 3 partially Medicare-subsidized departments run by private groups who also provided fully subsidized MR scanning in other centers. This arrangement covered a range of departments from large public hospitals to small private radiological clinics [15]. Out of these centers, only MR technologists who had at least 3 months of experience were invited to participate in the study. A questionnaire regarding the issues of occupational health of lone working MR technologists was distributed to each participant in person and collected through the same channel two weeks later. Their participation was voluntary and they could withdraw at any stage. This study was approved by the institutional ethics committee.

Yes/no, multiple choice (MC) and 5-point scale questions were developed for the questionnaire to obtain participants' demographic and departmental information, situations of lone working and perceptions on the issues of occupational health in relation to this area. The content of the questions was based on literature regarding lone working and MRI safety $[1,3,4,6,10,14]$. The questionnaire was piloted prior to distribution.

Descriptive and inferential statistics were applied to analyze the questionnaire data. The frequency was obtained for each choice in the yes/no and MC questions. Cross tabulations were used to determine any relationship 
between categorical variables. A Fisher's exact (for the $2 \times 2$ contingency table) or $\mathrm{Chi}^{2}$ test (for the larger table) was applied to determine the significance of any identified relationship. Means and standard deviations (SD) were calculated for interval data obtained from the 5-point scale questions. Responses were also divided into cohorts based on the demographic and departmental information (e.g. male and female) to calculate the individual means and SDs for each grouping. Mean values between cohorts were compared through either a t-test (for 2 groups) or one way analysis of variance (for 3 cohorts or more). GraphPad Instat 3 and Microsoft Excel 2007 were used in data analysis. A p-value less than 0.05 obtained from inferential statistics was considered statistically significant.

\section{RESULTS}

A total of 90 questionnaires were distributed to the identified WA MR technologists and 59 were returned yielding a response rate of $65.6 \%$. Table 1 summarizes the current situation of lone working in WA MRI departments. The majority of respondents $(76.3 \%, 45 / 59)$ work in private MRI departments. Around one third of their workplaces $(35.6 \%, 21 / 59)$ do not have MRI safety officers. Working as the only qualified MR technologist with other healthcare personnel in the vicinity is popular $(83.1 \%$, 49/59). More than half of them $(55.1 \%, 27 / 49)$ also experience lone working in the departments. These situations commonly happen before and after normal working hours for at least half day per week. MR technologists from the private sector are more likely to be required to work alone and the relationship between the type of workplace and the experience of lone working is statistically significant (Table 2).

Table 3 shows the MR technologists' perceptions on issues of occupational health related to lone working. Positive views are noted in the areas of adequacy of training and arrangement, confidence and comfort towards working alone, except the item of immediate emergency assistance (mean: 3). However, they also expressed

Table 1. Current situation of lone working among Western Australia magnetic resonance (MR) technologists

\begin{tabular}{lc}
\hline \multicolumn{1}{c}{ Question* } & $\begin{array}{c}\text { Frequency } \\
\mathrm{n}(\%)\end{array}$ \\
\hline $\begin{array}{l}\text { Demographic and department information } \\
\text { 1. Gender }(\mathrm{N}=59)\end{array}$ \\
$\quad$ male & $25(42.4)$ \\
female & $34(57.6)$ \\
2. Type of workplace $(\mathrm{N}=59)$ & \\
private & $45(76.3)$ \\
public & $14(23.7)$ \\
3. Position $(\mathrm{N}=59)$ & \\
full-time & $35(59.3)$ \\
part-time & $24(40.7)$ \\
4. MRI experience $(\mathrm{N}=59)$ & \\
$<1$ year & $5(8.5)$ \\
1-3 years & $16(27.1)$ \\
4-10 years & $20(33.9)$ \\
$>10$ years & $18(30.5)$ \\
\hline
\end{tabular}


Table 1. Current situation of lone working among Western Australia magnetic resonance (MR) technologists - cont.

\begin{tabular}{|c|c|}
\hline Question* & $\begin{array}{c}\text { Frequency } \\
\mathrm{n}(\%)\end{array}$ \\
\hline \multicolumn{2}{|l|}{ 5. MRI qualifications $(\mathrm{N}=57)^{\mathrm{a}}$} \\
\hline unqualified & $10(17.5)$ \\
\hline level one accreditation & $34(59.6)$ \\
\hline level two accreditation & $13(22.8)$ \\
\hline \multicolumn{2}{|c|}{ 6. Presence of MRI safety officer in the department $(\mathrm{N}=59)$} \\
\hline yes & $38(64.4)$ \\
\hline no & $21(35.6)$ \\
\hline \multicolumn{2}{|c|}{ 7. Incident reporting system in place in the department $(\mathrm{N}=59)$} \\
\hline yes & $58(98.3)$ \\
\hline no & $1(1.7)$ \\
\hline \multicolumn{2}{|c|}{ Situations of working alone and as the only qualified MR technologist ${ }^{\mathrm{b}}$} \\
\hline \multicolumn{2}{|c|}{ 8. Experience of working as the only qualified MR technologist $(\mathrm{N}=59)$} \\
\hline yes & $49(83.1)$ \\
\hline no & $10(16.9)$ \\
\hline \multicolumn{2}{|c|}{ 9. Time worked as the only qualified MR technologist per week $(\mathrm{N}=49)$} \\
\hline less than an hour & $2(4.1)$ \\
\hline half a day & $15(30.6)$ \\
\hline one day & $20(40.8)$ \\
\hline more than a day & $12(24.5)$ \\
\hline \multicolumn{2}{|c|}{ 10. Time of day working as the only qualified MR technologist $(\mathrm{N}=49)$} \\
\hline before normal working hours & $31(63.3)$ \\
\hline morning & $17(34.7)$ \\
\hline lunch time & $21(42.9)$ \\
\hline afternoon & $15(30.6)$ \\
\hline after normal working hours & $40(81.6)$ \\
\hline \multicolumn{2}{|l|}{ 11. Experience in lone working $(\mathrm{N}=49)$} \\
\hline yes & $27(55.1)$ \\
\hline no & $22(44.9)$ \\
\hline \multicolumn{2}{|l|}{ 12. Total time of lone working per week $(\mathrm{N}=26)^{\mathrm{a}}$} \\
\hline less than an hour & $6(23.1)$ \\
\hline half a day & $14(53.8)$ \\
\hline one day & $2(7.7)$ \\
\hline more than a day & $4(15.4)$ \\
\hline
\end{tabular}


Table 1. Current situation of lone working among Western Australia magnetic resonance (MR) technologists - cont.

\begin{tabular}{|c|c|}
\hline Question* & $\begin{array}{c}\text { Frequency } \\
\mathrm{n}(\%)\end{array}$ \\
\hline \multicolumn{2}{|l|}{ 13. Time of day working alone $(\mathrm{N}=27)$} \\
\hline before normal working hours & $15(55.6)$ \\
\hline morning & $8(29.6)$ \\
\hline lunch time & $6(22.2)$ \\
\hline afternoon & $8(29.6)$ \\
\hline after normal working hours & $13(48.1)$ \\
\hline
\end{tabular}

* Questions 9-11 are only required for respondents who answered "yes" in question 8 and questions 12 \& 13 are only applicable to those who chose "yes" in question 11.

MRI - magnetic resonance imaging.

${ }^{a}$ Missing response due to voluntary participation characteristic of the questionnaire.

${ }^{\mathrm{b}}$ Working alone - no other person in the entire MRI imaging area. Working as the only qualified MR technologist - including the presence of other healthcare personnel such as a nurse and an assistant in the vicinity.

Table 2. Relationship between the type of workplace and experience in lone working

\begin{tabular}{|c|c|c|c|}
\hline \multirow[t]{2}{*}{ Experience of lone working } & \multicolumn{2}{|c|}{$\begin{array}{c}\text { Type of workplace } \\
\text { Observed } \\
{[n(\text { expected n)] }}\end{array}$} & \multirow[t]{2}{*}{$\begin{array}{l}\text { Total } \\
\text { (n) }\end{array}$} \\
\hline & private sector & public hospital & \\
\hline Yes & $24(20.9)$ & $3(6.1)$ & 27 \\
\hline No & $14(17.1)$ & $8(4.9)$ & 22 \\
\hline Total (n) & 38 & 11 & 49 \\
\hline
\end{tabular}

Fisher's exact test, $\mathrm{p}<0.05$.

concerns in relation to safety of individuals and accidents happening in the vicinity, and prefer to work with another qualified MR technologist (mean: 3.8). Statistically significant variables that influence MR technologists' perceptions on these issues are demonstrated in Table 4. MR technologists working in the private sector have a less positive view on the adequacy of arrangement for lone working and consider immediate emergency assistance inadequate (Question 1). The presence of MRI safety officers and other healthcare personnel in the workplaces affect their safety-related concerns (Question 2).

Table 3. Magnetic resonance (MR) technologists' perceptions on issues of occupational health in relation to lone working

\begin{tabular}{lcc}
\hline \multicolumn{1}{c}{ Questions $^{\mathrm{a}}$} & $\begin{array}{c}\text { Frequency } \\
\mathrm{n}(\%)\end{array}$ & $\mathrm{M}^{\prime} \mathrm{SD}^{\mathrm{b}}$ \\
\hline 1. Perceived adequacy of lone working training received in relation to $(\mathrm{N}=57)^{\mathrm{c}}$ : & \\
a) first aid & $50(87.7)$ & - \\
yes & $7(14)$ & - \\
\hline no & & \\
\hline
\end{tabular}


Table 3. Magnetic resonance (MR) technologists' perceptions on issues of occupational health in relation to lone working - cont.

\begin{tabular}{|c|c|c|}
\hline Questions $^{\mathrm{a}}$ & $\begin{array}{c}\text { Frequency } \\
\mathrm{n}(\%)\end{array}$ & $\mathrm{M} \pm \mathrm{SD}^{\mathrm{b}}$ \\
\hline \multicolumn{3}{|l|}{ b) emergency management } \\
\hline yes & $48(84.2)$ & - \\
\hline no & $9(15.8)$ & - \\
\hline \multicolumn{3}{|l|}{ c) patient handling } \\
\hline yes & $50(87.7)$ & - \\
\hline no & $7(12.3)$ & - \\
\hline \multicolumn{3}{|l|}{ 2. Perceived adequacy of arrangement for lone working in relation toc: } \\
\hline a) first aid $(\mathrm{N}=56)$ & - & $3.3 \pm 1.1$ \\
\hline b) emergency guidelines $(\mathrm{N}=56)$ & - & $3.5 \pm 1.1$ \\
\hline c) immediate emergency assistance ( $\mathrm{N}=57)$ & - & $3 \pm 1.1$ \\
\hline 3. Ease of reporting incidents related to lone working $(\mathrm{N}=58)^{\mathrm{c}}$ & - & $3.9 \pm 0.9$ \\
\hline 4. Perceived confidence in lone working $(\mathrm{N}=54)^{\mathrm{c}}$ & & $3.8 \pm 0.9$ \\
\hline 5. Comfort with lone working $(\mathrm{N}=55)^{\mathrm{c}}$ & - & $3.6 \pm 0.9$ \\
\hline \multicolumn{3}{|l|}{ 6. Concern about lone working in relation to $(\mathrm{N}=55)^{\mathrm{c}}$ : } \\
\hline a) patient safety & - & $4 \pm 1.1$ \\
\hline b) safety of the personnel in the vicinity & - & $4 \pm 1.1$ \\
\hline c) accidents & - & $4 \pm 1.1$ \\
\hline 7. Preference to work with another qualified MR technologist $(\mathrm{N}=58)$ & - & $3.8 \pm 1.2$ \\
\hline \multicolumn{3}{|l|}{ 8. Concern about working as the only qualified MR technologist in relation to ${ }^{\mathrm{d}}$ : } \\
\hline a) patient safety $(\mathrm{N}=55)$ & - & $3.2 \pm 1.3$ \\
\hline b) safety of the personnel in the vicinity $(\mathrm{N}=56)$ & - & $3.1 \pm 1.3$ \\
\hline c) accidents $(\mathrm{N}=56)$ & - & $3.4 \pm 1.3$ \\
\hline
\end{tabular}

${ }^{a}$ At least one missing response is noted in each question due to voluntary participation characteristic of the questionnaire.

${ }^{\mathrm{b}}$ Scale from 1 to 5 - from strongly disagree to strongly agree.

${ }^{\mathrm{c}}$ Lone working - no other person in the entire MR imaging area.

${ }^{\mathrm{d}}$ Working as the only qualified MR technologist - including the presence of other healthcare personnel such as a nurse and an assistant in the vicinity. $\mathrm{M}$ - mean; SD - standard deviation.

Table 4. Comparison of magnetic resonance (MR) technologists' perceptions on issues of occupational health of lone working

\begin{tabular}{llcc}
\hline \multicolumn{1}{c}{ Question } & Cohort & $\mathrm{M} \pm \mathrm{SD}^{\mathrm{a}}$ & $\mathrm{p}$ \\
\hline 1. Adequacy of arrangement for lone working in relation to: & & & \\
a) emergency guidelines & private sector $(\mathrm{N}=43)$ & $3.3 \pm 1$ & $<0.05$ \\
& public hospital $(\mathrm{N}=13)$ & $4 \pm 1.1$ & \\
b) immediate emergency assistance & private sector $(\mathrm{N}=43)$ & $2.8 \pm 1$ & $<0.05$ \\
& public hospital $(\mathrm{N}=14)$ & $3.5 \pm 1.5$ & \\
\hline
\end{tabular}


Table 4. Comparison of magnetic resonance (MR) technologists' perceptions on issues of occupational health of lone working - cont.

\begin{tabular}{|c|c|c|c|}
\hline Question & Cohort & $\mathrm{M} \pm \mathrm{SD}^{\mathrm{a}}$ & $\mathrm{p}$ \\
\hline \multicolumn{4}{|l|}{ 2. Concern in relation to: } \\
\hline \multirow[t]{4}{*}{ a) patient safety } & with MRI safety officer $(\mathrm{N}=37)$ & $3.8 \pm 1.2$ & $<0.05$ \\
\hline & without MRI safety officer $(\mathrm{N}=18)$ & $4.5 \pm 0.7$ & \\
\hline & lone working $(\mathrm{N}=55)^{\mathrm{b}}$ & $4 \pm 1.1$ & $<0.0005$ \\
\hline & $\begin{array}{l}\text { working as the only qualified MR } \\
\text { technologist }(\mathrm{N}=56)^{c}\end{array}$ & $3.2 \pm 1.3$ & \\
\hline \multirow[t]{2}{*}{ b) safety of personnel in the vicinity } & lone working $(\mathrm{N}=55)^{\mathrm{b}}$ & $4 \pm 1.1$ & $<0.0001$ \\
\hline & $\begin{array}{l}\text { working as the only qualified MR } \\
\text { technologist }(\mathrm{N}=56)^{c}\end{array}$ & $3.1 \pm 1.3$ & \\
\hline \multirow[t]{2}{*}{ c) accidents } & lone working $(\mathrm{N}=55)^{\mathrm{b}}$ & $4 \pm 1.1$ & $<0.05$ \\
\hline & $\begin{array}{l}\text { working as the only qualified MR } \\
\text { technologist }(\mathrm{N}=56)^{c}\end{array}$ & $3.4 \pm 1.3$ & \\
\hline
\end{tabular}

MRI - magnetic resonance imaging.

$\mathrm{M}$ - mean; SD - standard deviation.

${ }^{a}$ Scale from 1 to 5 - from strongly disagree to strongly agree.

${ }^{\mathrm{b}}$ Lone working - no other person in the entire MR imaging area.

${ }^{c}$ Working as the only qualified MR technologist - including the presence of other healthcare personnel such as a nurse and an assistant in the vicinity.

\section{DISCUSSION}

The findings presented in Table 1 show that lone working is common among WA MR technologists. Around half of the respondents $(45.8 \%, 27 / 59)$ indicated they have this experience. Normally, they are required to work alone for at least half a day per week. Although it is recommended by ACR [3] and RANZCR [4] that MR technologists should not work alone, it would be difficult to change the situation because of the shortage of MRI specialists [16,17]. However, according to the Department of Education, Employment and Workplace Relations, Australia, neither MR nor medical imaging technologists are recognized as shortage occupations [18]. Since MR technologists form a rather small community, the importance of this issue in relation to occupational medicine and environmental health might be overlooked. Nonetheless, its prevalence appears to be high as shown in this study. Most importantly, the consequences of lone working in MRI departments have been identified as potentially catastrophic, for example, asphyxiation caused by cryogen, in spite of rare likelihood of their occurrence [9,19]. A significant risk is associated with this working situation [19]. It is expected this study could increase the awareness of the clinical community and, especially, employers.

Table 2 demonstrates that there is a statistically significant relationship between the type of workplace and experience of lone working, and MR technologists from the private sector are more frequently required to work alone than those employed by the public hospitals. It appears that lone working in WA MRI departments may be due to the type of workplace. The private MRI centers always have the financial incentive to arrange MR technologists to work alone. The pattern of lone working noted in this study (Table 1) is also similar to the situation reported by Bertermann and Martin [14]. In their study on workflow improvement for a private MRI center in Germany, they revealed that during around half of the opening hours of the center $(52.2 \%, 6 / 11.5)$, there was only one MR technologist on duty and each MR technologist 
was required to work alone for $3-3.5 \mathrm{~h}$ in a shift (i.e. around half a day) either from 7 a.m. to 10 a.m. or from 3 p.m. to $6: 30$ p.m. [14].

The WA MR technologists indicated that the lone working training and arrangement provided by their workplaces were adequate, and were confident and comfortable to take up this responsibility (question 7, Table 1 and questions 1-5, Table 3). Apparently, the current situation is not against the legal regulations governing lone working $[1,2,10]$. A closer look at the findings presented by Table 3 and 4 reveals several potential issues that need to be addressed. Statistically significant differences are noted between private and public MRI departments in the area of adequacy of arrangement for lone working including emergency guidelines and immediate emergency assistance, and the mean values from the private sector are lower than those from the public hospitals (question 1, Table 4). The immediate emergency assistance is considered inadequate even in the private MRI departments (mean: 2.8, question 1b, Table 4). Also, the respondents expressed concerns in relation to the safety of individuals in the vicinity and accidents occurring when working alone (mean: 4, question 6, Table 3). These concerns may become a source of anxiety and affect the employees' mental health [13]. Although the findings are only based on their perceptions and may not totally reflect the real situations, the employers should assume the responsibility to improve these issues $[1,2,10]$.

Two potential ways to address the MR technologists' concerns about lone working could be gathered from question 2, Table 4. Their concerns would become lower if the departments had MRI safety officers or if they could work with other healthcare professionals. Nonetheless, the position of an MRI safety officer is normally not required in a general MRI department [4]. This also explains why only around two thirds of the respondents' workplaces have MRI safety officers (question 6, Table 1). Although working as the only qualified MR technologist with other healthcare personnel such as a nurse and an assistant should not be considered as working alone, in the situation of workers required to carry out their duties without close or direct supervision it is also classified as lone working in the healthcare discipline [10]. When the only qualified MR technologist can work with other healthcare personnel, the MR technologist can receive immediate assistance from the colleague in case of emergency. This would address the issue noted in question 1, Table 4 as well. Although these two arrangements would increase the running costs of the MRI services and might not be feasible in the private sector, their effects are statistically significant (question 2, Table 4). A more financially viable approach could be just to provide an MRI assistant to each MR technologist required working alone [20].

This study only investigated the current situation of lone working in WA MRI departments based on the inputs from MR technologists provided through a self-report questionnaire. A further study should be conducted to obtain views from other related healthcare professionals such as radiologists and clinicians on this issue. A field study would be useful to provide a more objective assessment on the situation verifying the findings from the current study. Also, the study could be extended to other Australian states and countries. An evaluation of the effectiveness of employing MRI assistants in order to address the concerns of lone working MR technologists could be another direction for future research.

\section{CONCLUSIONS}

In conclusion, about 1 in 2 WA MR technologists has experienced lone working. Technologists from the private sector are more likely to be required to work alone. The training and arrangement provided by their employers seem to be generally adequate and hence may be considered as meeting the legal requirements. However, several areas should be improved by the workplaces (especially in the private sector). These include enhancement on immediate emergency assistance and concern relief. 


\section{ACKNOWLEDGMENTS}

The authors would like to thank all WA MR technologists who participated in this study for their contributions of time and effort.

\section{REFERENCES}

1. Commission for Occupational Safety and Health. Guidance note - Working alone. West Perth: Commission for Occupational Safety and Health; 2009.

2. Health and Safety Executive. Working alone: Health and safety guidance on the risks of lone working. Bootle: Health and Safety Executive; 2009.

3. Kanal E, Barkovich AJ, Bell C, Borgstede JP, Bradley Jr WG, Froelich JW, et al. ACR guidance document for safe MR practices: 2007. Am J Roentgenol. 2007;188:1-27, http://dx.doi.org/10.2214/AJR.06.1616.

4. The Royal Australian and New Zealand College of Radiologists (RANZCR). RANZCR MRI safety guidelines. Sydney: RANZCR; 2007.

5. ECRI Institute. 2010 top 10 technology hazards. Health Devices. 2009;38:1-10.

6. Pyke LM. Working alone in MRI? Policies to reduce risk when working alone in the MRI environment. Can J Med Radiat Technol. 2007;38:31-6, http://dx.doi.org/10.1016/ S0820-5930(09)60257-7.

7. Dempsey MF, Condon B, Hadley DM. MRI safety review. Semin Ultrasound CT MR. 2002;23:392-401, http://dx.doi. org/10.1016/S0887-2171(02)90010-7.

8. Consiglio N. MRI and patient safety. Can J Med Radiat Technol. 2006;37:5-9, http://dx.doi.org/10.1016/S08205930(09)60130-4.

9. De Wilde JP, Grainger D, Price DL, Renaud C. Magnetic resonance imaging safety issues including an analysis of recorded incidents within the UK. Prog Nucl Magn Reson Spectrosc. 2007;51:37-48, http://dx.doi.org/10.1016/j.pnmrs.2007.01.003.

10. Health and Safety Authority. Guidance on lone working in the healthcare sector. Dublin: Health and Safety Authority; 2011.
11. Ng K, Yeung J, Cheung I, Chung A, White P. Workplace violence - A survey of diagnostic radiographers working in public hospitals in Hong Kong. J Occup Health. 2009;51:355-63, http://dx.doi.org/10.1539/joh.O8021.

12. Shellock FG, Crues JV. MR procedures: Biologic effects, safety, and patient care. Radiology. 2004;232:635-52, http:// dx.doi.org/10.1148/radiol.2323030830.

13. Sun W, Fu J, Chang Y, Wang L. Epidemiological study on risk factors for anxiety disorder among Chinese doctors. J Occup Health. 2012;54:1-8, http://dx.doi.org/10.1539/ joh.11-0169-OA.

14. Bertermann B, Martin A. The implementation of syngo to improve the workflow in the MRI department of a large general radiology practice. Electromedica. 2003;71:24-7.

15. Department of Health and Ageing. MRI expansion summary of MRI units - Western Australia [cited 2013 Mar 11]. Available from: http://www.health.gov.au/internet/main/ publishing.nsf/content/di-mri-eligunits-wa.

16. The Lancet Oncology. Diagnostic imaging still threatened by shortages. Lancet Oncol. 2004;5:331, http://dx.doi. org/10.1016/S1470-2045(04)01475-5.

17. UK Border Agency. Appendix k: Shortage occupation list [cited 2012 Dec 11]. Available from: http://www.ukba.homeoffice.gov.uk/policyandlaw/immigrationlaw/immigrationrules/appendixk/.

18. Department of Education, Employment and Workplace Relations. Employment research and statistics: Skill shortages [cited 2012 Dec 11]. Available from: http://deewr.gov.au/ skill-shortages.

19. Swinburne University of Technology. MRI-09 health \& safety risk assessment [cited 2013 Nov 20]. Available from: http://www.swinburne.edu.au/lss/bpsyc/neuroimaging/documents/MRI-09.pdf.

20. National Health Service. Radiography assistants and imaging support workers [cited 2012 Dec 11]. Available from: http:// www.nhscareers.nhs.uk/explore-by-career/wider-healthcareteam/careers-in-the-wider-healthcare-team/clinical-supportstaff/radiography-assistantssupport-roles/.

This work is available in Open Access model and licensed under a Creative Commons Attribution-NonCommercial 3.0 Poland License - http://creativecommons.org/ licenses/by-nc/3.0/pl/deed.en. 